JAOS

JOURNAL OF APPLIED ORAL SCIENCE

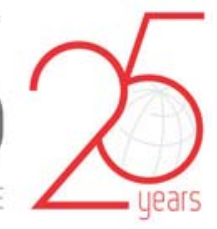

\title{
Degree of conversion and bond strength of resin-cements to feldspathic ceramic using different curing modes
}

\section{Abstract}

Veridiana Resende NOVAIS ${ }^{1}$

Luís Henrique Araújo RAPOSO ${ }^{2}$

Rafael Resende de MIRANDA ${ }^{3}$

Camila de Carvalho Almança LOPES ${ }^{3}$

Paulo Cézar SIMAMOTO JÚNIOR ${ }^{2}$

Carlos José SOARES ${ }^{1}$
Submitted: May 31, 2016 Modification: August 25, 2016 Accepted: September 26, 2016
Resin cements have led to great advances in dental ceramic restoration techniques because of their ability to bond to both dental structures and restorative materials. Objective: The aim of this study was to assess the performance of resin cements when different curing modes are used, by evaluating the degree of conversion and bond strength to a ceramic substrate. Material and Methods: Three resin cements were evaluated, two dual-cured (Variolink II and RelyX ARC) and one light-cured (Variolink Veneer). The dualcured resin cements were tested by using the dual activation mode (base and catalyst) and light-activation mode (base paste only). For degree of conversion (DC) $(n=5)$, a $1.0 \mathrm{~mm}$ thick feldspathic ceramic disc was placed over the resin cement specimens and the set was light activated with a QTH unit. After $24 \mathrm{~h}$ storage, the DC was measured with Fourier transform infrared spectroscopy (FTIR). For microshear bond strength testing, five feldspathic ceramic discs were submitted to surface treatment, and three cylindrical resin cement specimens were bonded to each ceramic surface according to the experimental groups. After $24 \mathrm{~h}$, microshear bond testing was performed at $0.5 \mathrm{~mm} / \mathrm{min}$ crosshead speed until the failure. Data were submitted to one-way ANOVA followed by Tukey test $(p<0.05)$. Scanning electron microscopy (SEM) was used for classifying the failure modes. Results: Higher DC and bond strength values were shown by the resin cements cured by using the dual activation mode. The Variolink II group presented higher DC and bond strength values when using light-activation only when compared with the Variolink Veneer group. Conclusion: The base paste of dual-cured resin cements in light-activation mode can be used for bonding translucent ceramic restorations of up to or less than $1.0 \mathrm{~mm}$ thick.

Keywords: Polymerization. Resin cements. Shear strength. 


\section{Introduction}

The ability of ceramics to match natural dentition due to their good physical and optical properties, makes them the material of choice for patients with high esthetic expectations ${ }^{17}$. Conservative ceramic restorations for changing the position, shape, or color of anterior teeth have been widely used in modern dental practice ${ }^{1}$. The success of ceramic veneers has been attributed to the establishment of a durable bond among tooth tissues, luting composite and ceramic substrate ${ }^{18}$.

Resin-based cements are the materials most commonly used for luting dental ceramic restorations, mainly because of their improved physicochemical properties. In general, these materials are composed of a polymeric matrix based on dimethacrylate monomers, filler particles and pigments ${ }^{9}$. Commercially available resin cements for luting ceramic veneers can be light activated or dual-cured, depending on the opacity and thickness of the ceramic restoration ${ }^{28}$. Light-cured resin cements allow extended working time and removal of the excess around the restoration before light-activation, reducing the time needed for finishing after restorations have been luted ${ }^{20}$. In addition to these features, light-cured resin cements have the great advantage of improved color stability, since no tertiary amines are used as chemical activator, which could cause color change over the time ${ }^{28}$.

Dual-cured resin cements were introduced to combine the advantages of light- and chemicallycured resin cements and are the most common luting materials used nowadays ${ }^{1}$. These systems are composed of a catalyst paste consisting of benzoyl peroxide (initiator) and base paste, containing a light-cured resin cement, in an endeavor to increase free radical concentration even under thick or opaque restorations ${ }^{28}$. The free radicals formed by the chemical reaction (tertiary amines/benzyl peroxide) would compensate for the lack of those that result from the physical initiation system activated by light (aliphatic amines/camphorquinone) ${ }^{11}$. However, dual-cured resin cements may have reduced color stability, due to the possibility of some degree of oxidation occurring in the components involved in chemical curing (tertiary amines) ${ }^{16}$.

Therefore, light-cured resin cements may be a more suitable option when luting thin translucent ceramic veneers ${ }^{29}$. Nonetheless, some dual-cured resin cement manufacturers offer a light-cured option for their systems in the absence of a light-cured resin cement, and indicate that dental practitioners should use the base paste only in a light-activation mode. However, there is still no evidence that the lightcured components of dual-cured resin cements have the ability to reach good physical and mechanical properties when used alone.

In addition to formulation, the success of ceramic restorations depends on optimal cure of resin cements. The degree of conversion is crucial in determining the mechanical performance of resin-based materials and their biocompatibility. The strength, elastic modulus, hardness and solubility of composite resins are directly related to the degree of conversion ${ }^{11}$. As seen, inadequate curing with a reduced degree of conversion may cause changes in the physical characteristics of resin-based components, affecting their mechanical properties, altering dimensional stability, decreasing bonding to tooth structures, capable of resulting in the unsatisfactory clinical performance of these materials ${ }^{25}$.

Therefore, the aim of this study was to assess the performance of resin cements when using different curing modes, by evaluating the degree of conversion and bond strength to a ceramic substrate. The hypothesis was that dual-cured resin cements used in the dual activation mode with base and catalyst pastes, would behave differently when using these cements in the light-activation mode with base paste only. A resin cement with a light-curing option only was also used for the comparisons.

\section{Material and methods}

For this study, three resin cements were evaluated, two dual-cured [Variolink II (VL), shade A3, Ivoclar Vivadent; Schaan, Liechtenstein; and RelyX ARC (RX), shade A3, 3M-ESPE; St. Paul, MN, USA], and one light-cured [Variolink Veneer (VL-V), shade High Value +3 , I voclar Vivadent]. Dual-cured resin cements were tested in the dual activation mode by mixing the base and catalyst pastes (BC), or in the lightactivation mode, by using the base paste only (B). The light-cured resin cement was tested only in the light-activation mode. Thus, five experimental groups were defined.

Twenty-six feldspathic ceramic discs (Super Porcelain EX-3 Speed, Enamel S3, Noritake Dental 
Supply Co Ltd; Nagoya, Aichi, Japan) were obtained, one of which was used to perform the degree of conversion test and 25 were used for microshear bond strength testing. The materials information is summarized in Figure 1 . The ceramic discs were produced in a stainless steel split matrix $(12.5 \mathrm{~mm}$ in diameter $\times 1.2 \mathrm{~mm}$ thick). The ceramic powder/ liquid ratio was used according to the manufacturer's instructions and the mixture was placed in the mold. The ceramic discs were submitted to a sintering cycle in an appropriate furnace (Alumini Press II, EDG; São Carlos, SP, Brazil), according to the firing schedule suggested by the manufacturer. In the conclusion of the procedure, ceramic disc dimensions were $10 \mathrm{~mm}$ in diameter and $1 \mathrm{~mm}$ thick.

\section{Degree of conversion}

For testing the degree of conversion (DC), resin cements were put into vinyl molds $(1 \mathrm{~mm}$ thick $\times 2$ $\mathrm{mm}$ inner diameter $\times 10 \mathrm{~mm}$ outer diameter). A Teflon mold was placed around the vinyl molds. Mylar strips (Quimidrol; J oinville, SC, Brazil) were used on bottom and top surfaces of the mold to ensure smoothness of the specimens, allow the ceramic disc to be placed over the resin cement and to avoid inhibition of polymerization by oxygen ${ }^{4}$. The ceramic disc and the tip of the light-curing unit were positioned over the resin cement specimens with the help of a Teflon ring. The diameter of the light wand tip was exactly the same diameter as that of the disc/sample. For the dual activation mode, the base and catalyst pastes of dual-cured resin cements were mixed according to the manufacturer's directions and then three minutes were waited for the self-cure reaction to occur. After this, all the groups were light-cured through the ceramic discs using a quartz-tungsten halogen (QTH) light-curing unit (Optilux 501, Kerr; Orange, CA, USA) at $800 \mathrm{~mW} / \mathrm{cm}^{2}$ output for $40 \mathrm{~s}$ (Figure 2). All specimens were stored under dry and dark conditions at $37^{\circ} \mathrm{C}$ for $24 \mathrm{~h}$. The $\mathrm{DC}$ of the specimens $(n=5)$ was determined using attenuated total reflectance/Fourier transform infrared spectroscopy (ATR/FTIR, Vertex 70, Bruker; Ettlingen, Baden-Württemberg, Germany). A preliminary readout of each uncured material was recorded in absorbance spectrum acquired by scanning the specimens 32 times over a range from 4000 to $400 \mathrm{~cm}^{-1}$ with a resolution of $4 \mathrm{~cm}^{-1}$. An additional spectrum was acquired of the cured specimen after dry storage at $37^{\circ} \mathrm{C}$ for $24 \mathrm{~h}$, shielded from ambient light. The DC was calculated according to the following formula, using the absorption peak of the $\mathrm{C}=\mathrm{O}$ ester groups as reference, because no aromatic peaks were identified in Variolink Veneer:

$$
\% D C=100\left[1-\left(A a_{(C=C)} A b_{(C=O)} / A b_{(C=C)} A a_{(C=O)}\right)\right]
$$

\begin{tabular}{|c|c|c|c|c|}
\hline $\begin{array}{c}\text { Product } \\
\text { (lot number) }\end{array}$ & Material & Manufacturer & Shade & Composition* \\
\hline $\begin{array}{l}\text { Super Porcelain } \\
\text { EX-3 Speed } \\
\text { (033689) }\end{array}$ & $\begin{array}{l}\text { Feldspathic } \\
\text { ceramic }\end{array}$ & $\begin{array}{l}\text { Noritake Kizai Co. } \\
\text { Ltd., Nishi-Ku, } \\
\text { Nagoya, Japan }\end{array}$ & Enamel S3 & $\begin{array}{c}\mathrm{Si}-8.83 \%, \mathrm{C}-19.86 \%, \mathrm{O}-19.35 \%, \mathrm{~F}-0.95 \%, \mathrm{Na}-6.94 \%, \mathrm{Mg} \\
-0.33 \%, \mathrm{Al}-3.41 \%, \mathrm{~K}-0.53 \% .\end{array}$ \\
\hline $\begin{array}{l}\text { RelyX ARC } \\
\text { (N541931) }\end{array}$ & $\begin{array}{l}\text { Dual-cured } \\
\text { resin cement }\end{array}$ & $\begin{array}{l}\text { 3M-ESPE St. Paul, } \\
\text { MN, USA }\end{array}$ & A3 & $\begin{array}{c}\text { Paste A: Silane-treated ceramic, TEGDMA, Bis- } \\
\text { GMA, photoinitiators, amine, silane-treated } \\
\text { silica, functionalized dimethacrylate polymer. } \\
\text { Paste B: Silane-treated ceramic, TEGDMA, Bis-GMA, silane- } \\
\text { treated silica, benzoyl peroxide, functionalized dimethacrylate } \\
\text { polymer. }\end{array}$ \\
\hline $\begin{array}{c}\text { Variolink II } \\
\text { (base: J24343; } \\
\text { catalyst: J19503) }\end{array}$ & $\begin{array}{c}\text { Dual-cured } \\
\text { resin cement }\end{array}$ & $\begin{array}{l}\text { Ivoclar Vivadent, } \\
\text { Schaan, } \\
\text { Liechtenstein }\end{array}$ & A3 & $\begin{array}{c}\text { Paste A: Bis-GMA, urethane dimethacrylate, TEGDMA, } \\
\text { inorganic filler, ytterbium trifluoride, initiator, stabilizer. } \\
\text { Pasta B: Bis-GMA, UDMA, TEGDMA, inorganic filler, ytterbium } \\
\text { trifluoride, benzoyl peroxide, stabilizer. }\end{array}$ \\
\hline $\begin{array}{l}\text { Variolink } \\
\text { Veneer } \\
\text { (R77030) }\end{array}$ & $\begin{array}{l}\text { Light-cured } \\
\text { resin cement }\end{array}$ & $\begin{array}{l}\text { Ivoclar Vivadent, } \\
\text { Schaan, } \\
\text { Liechtenstein }\end{array}$ & $\begin{array}{l}\text { High Value } \\
\quad+3\end{array}$ & $\begin{array}{l}\text { Dimethacrylates, inorganic fillers (silica, barium glass, ytterbium } \\
\text { trifluoride), catalysts and stabilizers, pigments. }\end{array}$ \\
\hline $\begin{array}{l}\text { Monobond S } \\
\text { (N15269) }\end{array}$ & Silane & $\begin{array}{l}\text { Ivoclar Vivadent, } \\
\text { Schaan, } \\
\text { Liechtenstein } \\
\end{array}$ & $\begin{array}{l}\text { Colorless } \\
\text { liquid }\end{array}$ & $\begin{array}{l}\text { One-bottle silane ( } \approx 1 \% \text { 3-methacryloyloxypropyltrimethoxy } \\
\text { silane). }\end{array}$ \\
\hline $\begin{array}{l}\text { Acid Porcelain } \\
\text { Etchant } \\
(387314)\end{array}$ & $\begin{array}{l}10 \% \\
\text { hydrofluoric } \\
\text { acid }\end{array}$ & $\begin{array}{l}\text { Maquira Dental } \\
\text { Products, Maringá, } \\
\text { PR, Brazil }\end{array}$ & Red gel & $\begin{array}{l}\text { Hydrofluoric acid } 10 \% \text {, thickening agent, red dye and purified } \\
\text { water. }\end{array}$ \\
\hline
\end{tabular}

${ }^{*}$ According to manufacturers. Si - silicon; C - carbon; O - oxygen; $\mathrm{F}$ - fluorine; $\mathrm{Na}$ - sodium; $\mathrm{Mg}$ - magnesium; $\mathrm{Al}$ - aluminum; $\mathrm{K}$ potassium; Bis-GMA: 2,2-bis[p-(2'-hydroxy-3'methacryloxypropoxy)phenyl]propane; TEGDMA: triethylene glycol dimethacrylate; UDMA: 1,6-bis(methacryloxy-2-ethoxycarbonylamino)-2,4,4-trimethylhexane

Figure 1- Materials used in this study 


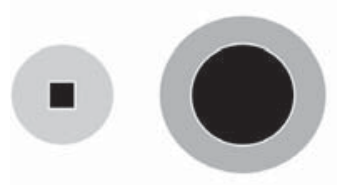

A

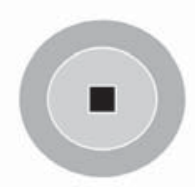

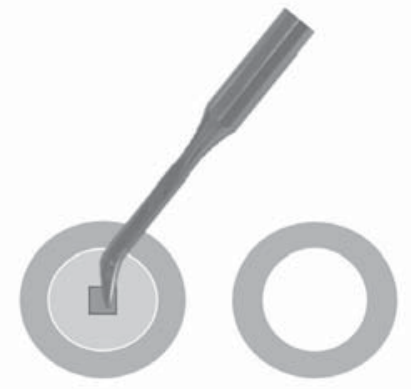

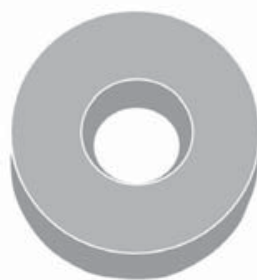

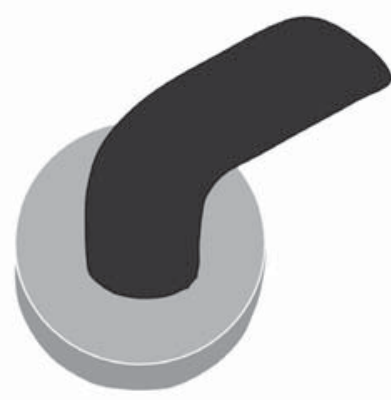

Figure 2- Preparation of specimens for degree of conversion: A- Vinyl mold; B- Teflon mold; C- Teflon mold positioned around vinyl mold; D- Insertion of resin cement into vinyl mold; E- Ceramic disc positioned over the resin cement specimen; F- Teflon ring positioned around the ceramic disc; G- Light-curing of resin cement through ceramic disc using a QTH unit

\section{Microshear bond strength}

Twenty-five ceramic discs were embedded in PVC cylinders using polyester resin (AM 190 resin, AeroJ et; São Paulo, SP, Brazil). After divesting, the ceramic disc surfaces were sequentially polished using silicon-carbide papers (\#600, 800, 1200 and 2000 grit sizes; Norton; Campinas, SP, Brazil), mounted on a water-cooled polisher (Aropol 2V, Arotec S/A; São Paulo, SP, Brazil). The discs were submitted to surface treatment with $10 \%$ hydrofluoric acid (Maquira Dental Products; Maringá, PR, Brazil) for $2 \mathrm{~min}^{27}$. The acid was removed with air/water spray and the specimens were cleaned in an ultrasonic bath (USC1400, Unique; Indaiatuba, SP, Brazil) with distilled water for 5 min. After drying the specimens, a layer of silane coupling agent (Monobond S, I voclar Vivadent) was applied and left to react for $1 \mathrm{~min}$.

The discs were randomly divided according to the five experimental groups. Three Tygon tubes $(0.5 \mathrm{~mm}$ high $\times 0.75 \mathrm{~mm}$ in diameter) were placed in parallel on each ceramic disc and filled with resin cement. For the dual activation mode, the cement was light-activated three minutes after it was inserted ${ }^{24}$. The specimens were light-cured by using the QTH unit at $800 \mathrm{~mW}$ / $\mathrm{cm}^{2}$ output for $40 \mathrm{~s}$, with the light source placed at the top of the specimens, and within a Teflon ring, thus light-curing all the resin cylinders simultaneously (Figure 3). All specimens were stored under relative humidity and dark conditions at $37^{\circ} \mathrm{C}$ for $24 \mathrm{~h}$, and after storage, the Tygon tubes were removed using a scalpel blade No. 12 .

Microshear testing $(n=5)$ was performed in a mechanical testing machine (Microtensile OM100, Odeme Dental Research; Luzerma, SC, Brazil), in which each ceramic disc was attached to a flat base by means of cyanoacrylate- based glue (Super Bonder, Loctite; Itapevi, SP, Brazil). A stainless steel wire (0.2 $\mathrm{mm}$ in diameter) (Morelli Ortodontia; Sorocaba, SP, Brazil) was placed around the resin cement cylinder at its base, as close as possible to the ceramic/ resin cement interface. The test was performed at a crosshead speed of $0.7 \mathrm{~mm} / \mathrm{min}$ until failure of the specimens.

\section{Failure mode analysis}

The failure mode of the specimens was analyzed by scanning electron microscopy (SEM) (TM3000, Hitachi High-Technologies Co.; Tokyo, Kantō, Japan) at 200x magnification, at an acceleration voltage of $25 \mathrm{kV}$. The failure modes were classified as: I- adhesive failure; II- cohesive failure at resin cement; III- cohesive failure at ceramic substrate; IV- mixed failure with predominance of resin cement; $V$ - mixed failure with predominance of ceramic substrate. Adhesive failure was characterized as a fault at the junction between the ceramic and the resin cement; cohesive failure when there was a fracture in the body of the cement or the ceramic; and mixed failure when there was cohesion failure in both materials, simultaneously.

\section{Statistical analysis}

Degree of conversion and microshear bond strength data were individually analyzed by one-way analysis of variance (ANOVA). Tukey post hoc tests were performed to determine differences among groups. Statistical significance was set at $\alpha=0.05$. Descriptive analysis was used for failure mode. 


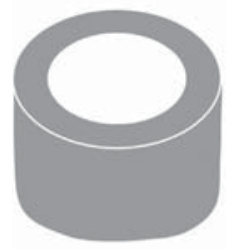

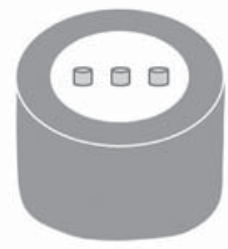

B

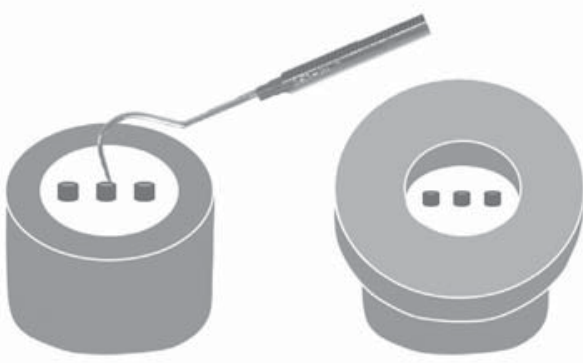

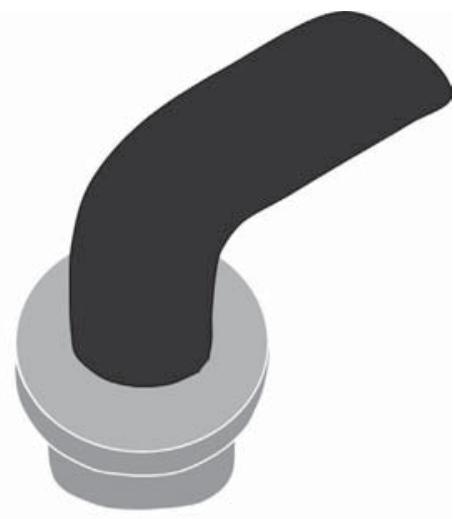

Figure 3- Preparation of specimens for microshear bond strength: A- Ceramic disc embedded in polyester resin cylinder; B-After surface treatment, three Tygon tubes were placed on each ceramic disc; C- Insertion of resin cement into Tygon tubes; D- Teflon ring positioned over the ceramic disc and around Tygon tubes; E- Light-curing of resin cement specimens using a QTH unit

Table 1- Mean degree of conversion (\%) and standard deviation for the experimental groups

\begin{tabular}{cc}
\hline Resin Cement & Degree of Conversion (\%) \\
\hline RX-BC & $72.8(3.7)^{\mathrm{A}}$ \\
\hline RX-B & $57.5(4.4)^{\mathrm{C}}$ \\
\hline VL-BC & $65.7(2.9)^{\mathrm{B}}$ \\
\hline VL-B & $58.3(2.1)^{\mathrm{C}}$ \\
\hline VL-V & $48.6(4.1)^{\mathrm{D}}$ \\
\hline
\end{tabular}

Means followed by different letters indicate statistically significant difference $(p<0.05)$

Table 2- Mean bond strength ( $\mu$ SBS) values and standard deviation for the experimental groups

\begin{tabular}{cc}
\hline Resin Cement & Bond Strength \\
\hline RX-BC & $33.5(2.8)^{\mathrm{AB}}$ \\
RX-B & $27.8(4.6)^{\mathrm{C}}$ \\
VL-BC & $36.5(4.7)^{\mathrm{A}}$ \\
VL-B & $36.0(2.0)^{\mathrm{A}}$ \\
VL-V & $29.8(2.0)^{\mathrm{BC}}$ \\
\hline
\end{tabular}

Means followed by different letters indicate statistically significant difference $(p<0.05)$

\section{Results}

\section{Degree of conversion}

The mean degree of conversion (\%) and standard deviation obtained for the experimental groups are shown in Table 1. Significant differences were observed among the groups $(p<0.001)$. The resin cements used in the dual activation mode (base and catalyst) showed higher DC values. The base paste of the dual-cured cements used in the light-activation mode presented intermediate DC values. The light-cured resin cement showed lower DC values when compared with the other cements.

\section{Microshear bond strength}

The mean bond strength values and standard deviation are shown in Table 2. The Variolink II groups, activated in dual mode or light-activation mode only showed the highest bond strength values, with similar results between them; and were similar to those of RelyX ARC in dual activation mode. The light-cured resin cement Variolink Veneer presented similar values to those of RelyX ARC in the dual activation mode and also to RelyX ARC in the light-activation mode.

\section{Failure mode}

The failure mode analysis shown in Figures 4 and 5 showed prevalence of cohesive failures in the ceramic substrate (Type III) for the resin cements used in the dual activation mode as well as for the Variolink Veneer light-cured cement. A higher percentage of cohesive failures in resin cement (Type II) or mixed failures with predominance of resin cement (Type IV) were observed for RelyX ARC when using the light-activation mode. No dominant failure mode was verified for the Variolink II in the light-activation mode.

\section{Discussion}

The hypothesis tested was accepted. The dualcured resin cements showed a higher degree of conversion (DC) and at least similar bond strength values when used in the dual activation mode (base and catalyst) when compared with the resin cements used in the light-activation mode (base paste only). The base paste of both the dual-cured resin cements presented higher DC and bond strength values than the light-cured resin cement tested. Moreover, it is important to note that the base paste of Variolink II 


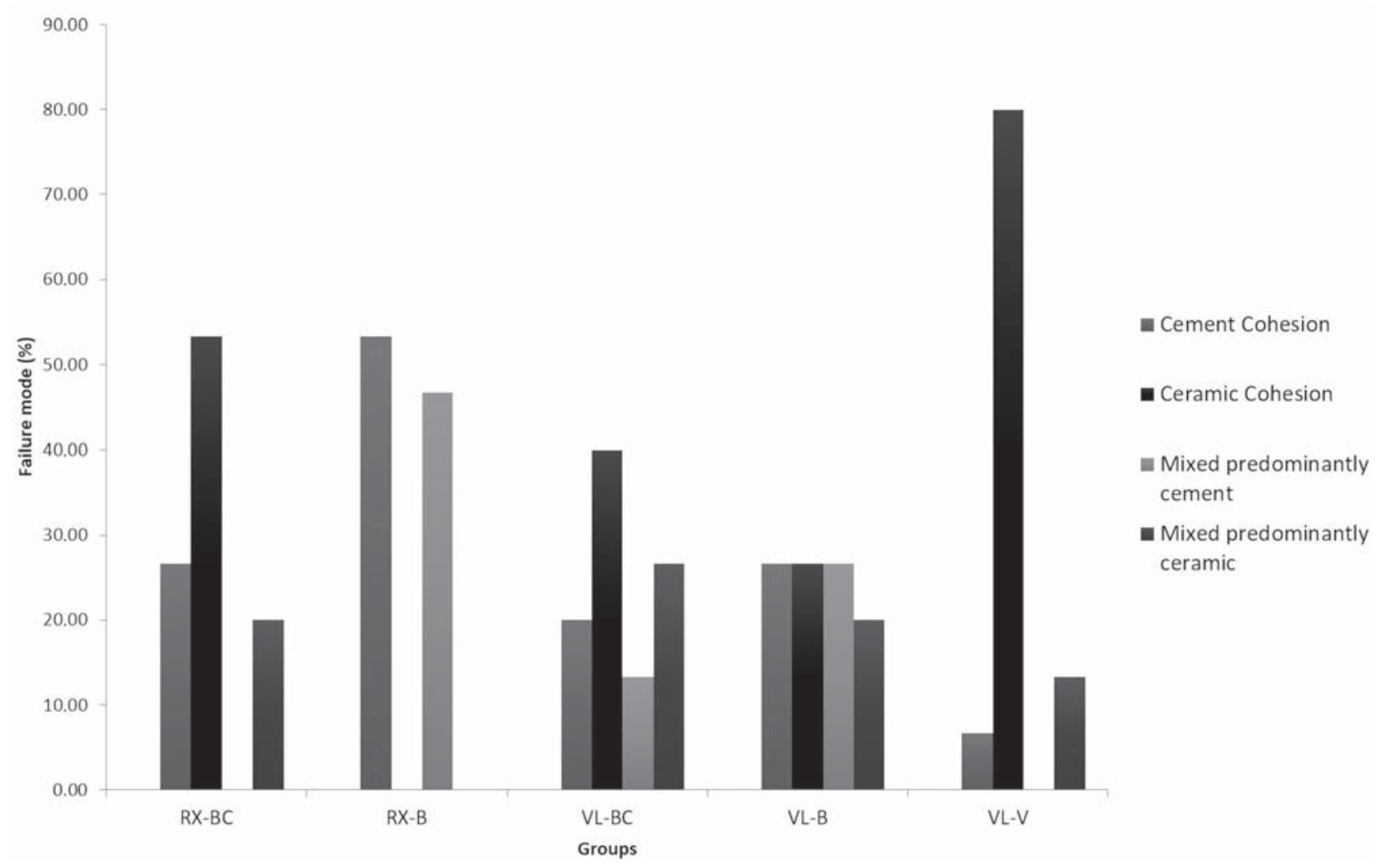

Figure 4- Failure mode distribution (\%) for the experimental groups
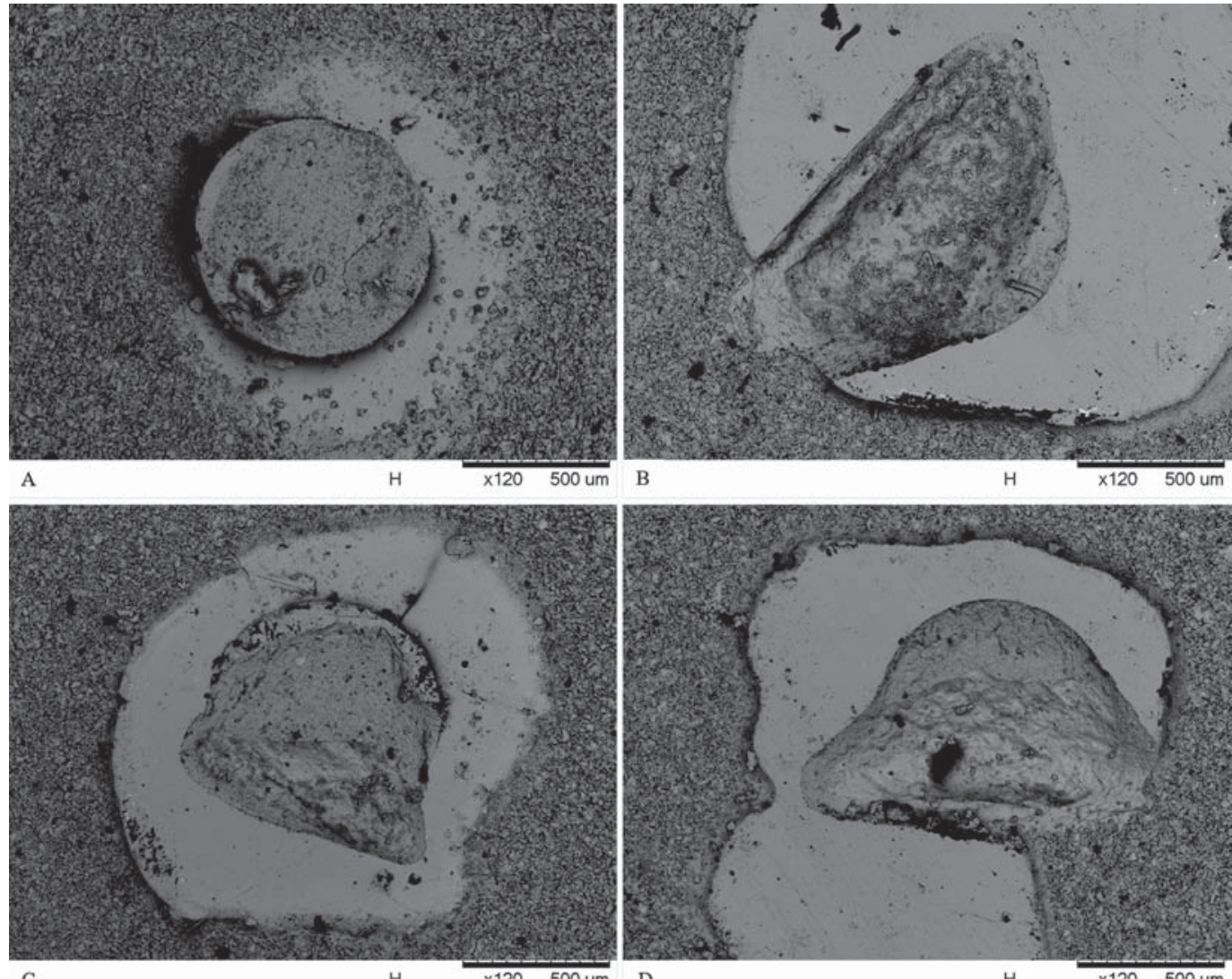

Figure 5- Examples of failure modes of the VL-BC group: A- cohesive failure at resin cement; B- cohesive failure at ceramic substrate; C- mixed failure with predominance of resin cement; D- mixed failure with predominance of ceramic substrate 
showed higher bond strength values than the base paste of RelyX ARC; and to consider that not all resin cements are equal in formulation and may present different curing properties ${ }^{10}$.

When comparing the resin cements using only the base paste in the light-activation mode, there were no significant differences between the DC of RelyX ARC and Variolink II. However, the DC of both resin cements was reduced in the light-activation compared with the dual activation mode. Therefore, the importance of a chemical activation in addition to light curing in dualcured resin cements must be emphasized. Previous studies have shown the importance of dual-curing resin cements for clinical situations in which the light from the curing unit is not capable of fully reaching all regions of the cavity or preparation, such as in the apical region of root canals during adhesive post luting or the deep internal areas of preparations for indirect adhesive restorations ${ }^{2,5,6,14}$. Thus, when the manufacturer informs that a cement is dual-cured, it is imperative to respect the instruction to perform the double polymerization process, in order to achieve higher DC values and improved properties in daily practice.

Composite-based restorative materials are constantly submitted to agents present in saliva, food and drinks, which may help to degrade the organic matrix ${ }^{21}$. The inadequate polymerization of resin cements, represented by a low DC, may result in increased dissolution of some components in the oral cavity, which may cause pulp sensitivity, in addition to a faster marginal degradation process and early loss of the indirect restoration ${ }^{13,22}$. A high DC ensures the best chemical and physical properties of resin cements ${ }^{26}$.

Variables such as color, thickness and type of ceramic for indirect restorations may interfere in the amount of light reaching the resin-based luting material, influencing the $D C^{15,25}$. Thus, for the DC methodology of this study, a feldspathic ceramic disc was interposed between the resin cement and the light source during curing of the specimens, seeking to emulate what happens in the oral cavity during clinical practice. In this study, it was shown that for cases in which a light-curing resin cement is required, the base pastes of the dual-cured resin cements evaluated used in the light-activation mode showed suitable properties that may allow their use for luting thin ceramic restorations.

Variolink II activated in both dual and light- activation modes showed the highest bond strength values, followed by RelyX ARC in the dual activation mode. In turn, when used in the light-activation mode with the base paste only, RelyX ARC presented values close to the lowest bond strength values, but these were statistically similar to those verified for the light-cured resin cement Variolink Veneer. Despite presenting a suitable bond strength to dental substrates, it is also important for resin cements to offer adequate bond strength to indirect restorations. Bonding to ceramic restorations follows similar principles as those used for bonding to dental tissues. The adhesive or resin cement infiltrates into the roughness created on the surface of these materials, thus enabling micro-mechanical retention ${ }^{19}$.

For this purpose, acid-sensitive ceramics are submitted to surface etching with hydrofluoric acid to increase the surface roughness, improve wettability, surface free energy, and to expose a silicon oxide network ${ }^{3,7}$. Additionally, to assure interaction between the ceramic and resin cement, the application of a coupling agent based on methacryloxypropyltrimethoxysilane allows the formation of covalent bonds between the silica from glass ceramics and the organic matrix from resin cements $^{8}$. The silane coupling agent is also capable to increase wettability and surface energy on the ceramic surface ${ }^{12,23}$.

Regarding the failure mode, dual-activated resin cements (VL-BC and RX-BC) and light-cured resin cement (VL-V) predominantly presented cohesive failures in the ceramic surface of the specimens, characterized as a body failure of the restorative material. This probably occurred because a conventional feldspathic ceramic without any reinforcement was used as the substrate material for bonding tests and also due to the higher bond strengths achieved in these specimens. RX-B specimens presented more cohesive failures involving the resin cement, with body failures in the luting agent. VL-B exhibited heterogeneous failure modes that were not conclusive. No classical adhesive failures were observed for the experimental groups. Therefore, despite the mechanical properties evaluated in this study showing that there were no significant differences between light-cured resin cement and dual-cured resin cements used in the light-activation mode, no favorable failure mode was observed for RX-B and VL-B. Thus, more studies are necessary to evaluate other properties that justify 
their use in clinical practice.

Although further studies are still needed, the use of dual-cured resin cements used only in the lightactivation mode may be an alternative for luting translucent ceramic restorations up to or less than $1.0 \mathrm{~mm}$ thick. The degree of conversion and bond strength showed similar behavior between base paste of dual-cured materials and light-cured resin cement. Furthermore, it is important to understand the chemical and mechanical properties of resin cements and the strategies capable of improving these properties, to ensure the success of restorative procedure.

\section{Acknowledgments}

The authors are grateful to FAPEMIG for financial support.

\section{References}

1- Archegas LR, Menezes Caldas DB, Rached RN, Soares P, Souza EM. Effect of ceramic veneer opacity and exposure time on the polymerization efficiency of resin cements. Oper Dent. 2012;37(3):2819.

2- Arrais CA, Giannini M, Rueggeberg FA, Pashley DH. Microtensile bond strength of dual-polymerizing cementing systems to dentin using different polymerizing modes. J Prosthet Dent. 2007;97(2): 99-106.

3- Blatz MB, Sadan A, Kern M. Bonding to silica-based ceramics: clinical and laboratory guidelines. Quintessence Dent Technol. 2002;25:54-62. 4- Bueno AL, Arrais CA, Jorge AC, Reis AF, Amaral CM. Light-activation through indirect ceramic restorations: does the overexposure compensate for the attenuation in light intensity during resin cement polymerization? J Appl Oral Sci. 2011;19(1):22-7.

5- Cerutti F, Acquaviva PA, Gagliani M, Ferrari M, Mangani F, Depero LE, et al. Degree of conversion of dual-cure resins light-cured through glass-fiber posts. Am J Dent. 2011;24(1):8-12.

6- Daleprane B, Nemesio de Barros Pereira C, Oréfice RL, Bueno AC, Vaz RR, Moreira AN, et al. The effect of light-curing access and different resin cements on apical bond strength of fiber posts. Oper Dent. 2014;39(2): E93-100.

7- Debnath S, Wunder SL, McCool JI, Baran GR. Silane treatment effects on glass/resin interfacial shear strengths. Dent Mater $2003 ; 19(5): 441-8$.

8- Della-Bona A. Characterizing ceramics and the interfacial adhesion to resin: II- the relationship of surface treatment, bond strength, interfacial toughness and fractography. J Appl Oral Sci. 2005; 13(2): 101-9

9- Ferracane JL, Greener EH. The effect of resin formulation on the degree of conversion and mechanical properties of dental restorative resins. J Biomed Mater Res. 1986;20(1):121-31.

10- Gajewski VE, Pfeifer CS, Fróes-Salgado NR, Boaro LC, Braga RR. Monomers used in resin composites: degree of conversion, mechanical properties and water sorption/solubility. Braz Dent J. 2012;23(5):50814.

11- Hofmann N, Renner J, Hugo B, Klaiber B. Elution of leachable components from resin composites after plasma arc vs standard or soft-start halogen light irradiation. J Dent. 2002;30(5-6):223-32.
12- Kitayama S, Nikaido T, Takahashi R, Zhu L, Ikeda M, Foxton RM, et al. Effect of primer treatment on bonding of resin cements to zirconia ceramic. Dent Mater. 2010;26(5):426-32

13- Kuguimiya RN, Rode KM, Carneiro PM, Aranha AC, Turbino $M L$. Influence of curing units and indirect restorative materials on the hardness of two dual-curing resin cements evaluated by the nanoindentation test. J Adhes Dent. 2015;17(3):243-8.

14- Lohbauer U, Pelka M, Belli R, Schmitt J, Mocker E, Jandt KD, et al. Degree of conversion of luting resins around ceramic inlays in natural deep cavities: a micro-Raman spectroscopy analysis. Oper Dent. 2010; 35(5): 579-86

15- Lopes CC, Rodrigues RB, Silva AL, Simamoto Júnior PC, Soares CJ, Novais VR. Degree of conversion and mechanical properties of resin cements cured through different all-ceramic systems. Braz Dent J. 2015;26(5): 484-9.

16- Lu H, Powers J M. Color stability of resin cements after accelerated aging. Am J Dent. 2004;17(5):354-8.

17- Olivera $A B$, Marques $M M$. Esthetic restorative materials and opposing enamel wear. Oper Dent. 2008;33(3):332-7.

18- Peumans M, Van Meerbeek B, Lambrechts P, Vanherle G. Porcelain veneers: a review of the literature. J Dent. 2000;28(3): 163-77.

19- Rashid $\mathrm{H}$. The effect of surface roughness on ceramics used in dentistry: a review of literature. Eur J Dent. 2014;8(4):571-9. 20- Scotti N, Comba A, Cadenaro M, Fontanive L, Breschi L, Monaco $C$, et al. Effect of lithium disilicate veneers of different thickness on the degree of conversion and microhardness of a light-curing and a dual-curing cement. Int J Prosthodont. 2016;29(4):384-8.

21- Sideridou ID, Karabela MM, Vouvoudi EC, Papanastasiou GE. Sorption and desorption parameters of water or ethanol in light-cured dental dimethacrylate resins. J Appl Polym Sci. 2008;107(1):463-75. 22- Silva EM, Noronha-Filho JD, Amaral CM, Poskus LT, Guimarães JG. Long-term degradation of resin-based cements in substances present in the oral environment: influence of activation mode. J Appl Oral Sci. 2013;21(3):271-7.

23- Smith RL, Villanueva C, Rothrock JK, Garcia-Godoy CE, Stoner $B R$, Piascik JR, et al. Long-term microtensile bond strength of surface modified zirconia. Dent Mater. 2011;27(8):779-85.

24- Soares CJ, Bicalho AA, Verissimo C, Soares PBF, Tantbirojn $D$, Versluis A. Delayed photo-activation effects on mechanical properties of dual cured resin cements and finite element analysis of shrinkage stresses in teeth restored with ceramic inlays. Oper Dent. 2016; 41(5): 491-500.

25- Soares CJ, Silva NR, Fonseca RB. Influence of the feldspathic ceramic thickness and shade on the microhardness of dual resin cement. Oper Dent. 2006;31(3):384-9.

26- Souza G, Braga RR, Cesar PF, Lopes GC. Correlation between clinical performance and degree of conversion of resin cements: a literature review. J Appl Oral Sci. 2015;23(4):358-68.

27- Steinhauser HC, Turssi CP, Franca FM, Amaral FL, Basting RT. Microshear bond strength and surface micromorphology of a feldspathic ceramic treated with different cleaning methods after hydrofluoric acid etching. J Appl Oral Sci. 2014;22(2):85-90

28- Tanoue N, Koishi $Y$, Atsuta M, Matsumura H. Properties of dualcurable luting composites polymerized with single and dual curing modes. J Oral Rehabil. 2003; 30(10): 1015-21.

29- Turgut S, Bagis B. Effect of resin cement and ceramic thickness on final color of laminate veneers: an in vitro study. J Prosthet Dent. 2013; 109(3): 179-86 